\title{
Isolated intrapulmonary teratoma
}

Callistus Ditah, MD, ${ }^{\mathrm{a}}$ Thomas Templin, MD, ${ }^{\mathrm{a}}$ Rakesh Mandal, MBBS, MS, MPH,

Jason W. Pinchot, MD, ${ }^{\mathrm{c}}$ and Ryan A. Macke, MD, ${ }^{\mathrm{a}}$ Madison, Wis

From the Departments of ${ }^{\mathrm{a}}$ Surgery, ${ }^{\mathrm{b}}$ Pathology and Laboratory Medicine, and ${ }^{\mathrm{c}}$ Radiology, University of Wisconsin School of Medicine and Public Health, Madison, Wis.

Disclosures: Authors have nothing to disclose with regard to commercial support.

Received for publication May 22, 2016; revisions received July 18, 2016; accepted for publication July 27, 2016; available ahead of print Aug 28, 2016.

Address for reprints: Ryan A. Macke, MD, Division of Cardiothoracic Surgery, Department of Surgery, University of Wisconsin School of Medicine and Public Health, 600 Highland Ave, H4 318/CSC, Madison, WI 53792 3236 (E-mail: macke@surgery.wisc.edu).

J Thorac Cardiovasc Surg 2016;152:e129-31

$0022-5223 / \$ 36.00$

Copyright @ 2016 by The American Association for Thoracic Surgery

http://dx.doi.org/10.1016/j.jtcvs.2016.07.056

\begin{tabular}{|l|l|}
\hline TICM \\
VIDEO \\
CLIP
\end{tabular}

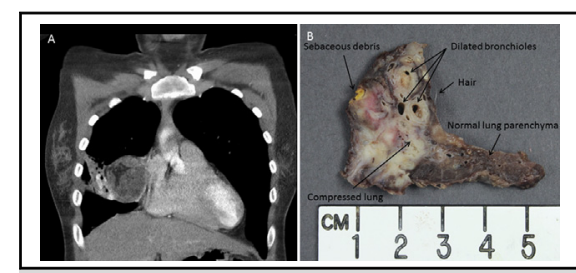

A, Computed tomography. B, Gross specimen images of an isolated intrapulmonary teratoma.

Central Message

Isolated intrapulmonary teratomas are extremely rare. Resection typically is required for diagnosis, and in cases of mature teratomas, it is curative.

See Editorial Commentary page e133.
Intrathoracic teratomas typically are located in the anterior mediastinum. In rare instances, isolated intrapulmonary teratomas without mediastinal extension have been reported. To date, fewer than 100 cases have been identified in the medical literature. ${ }^{1-4}$ We report a case of a 19year-old woman presenting with hemoptysis and an
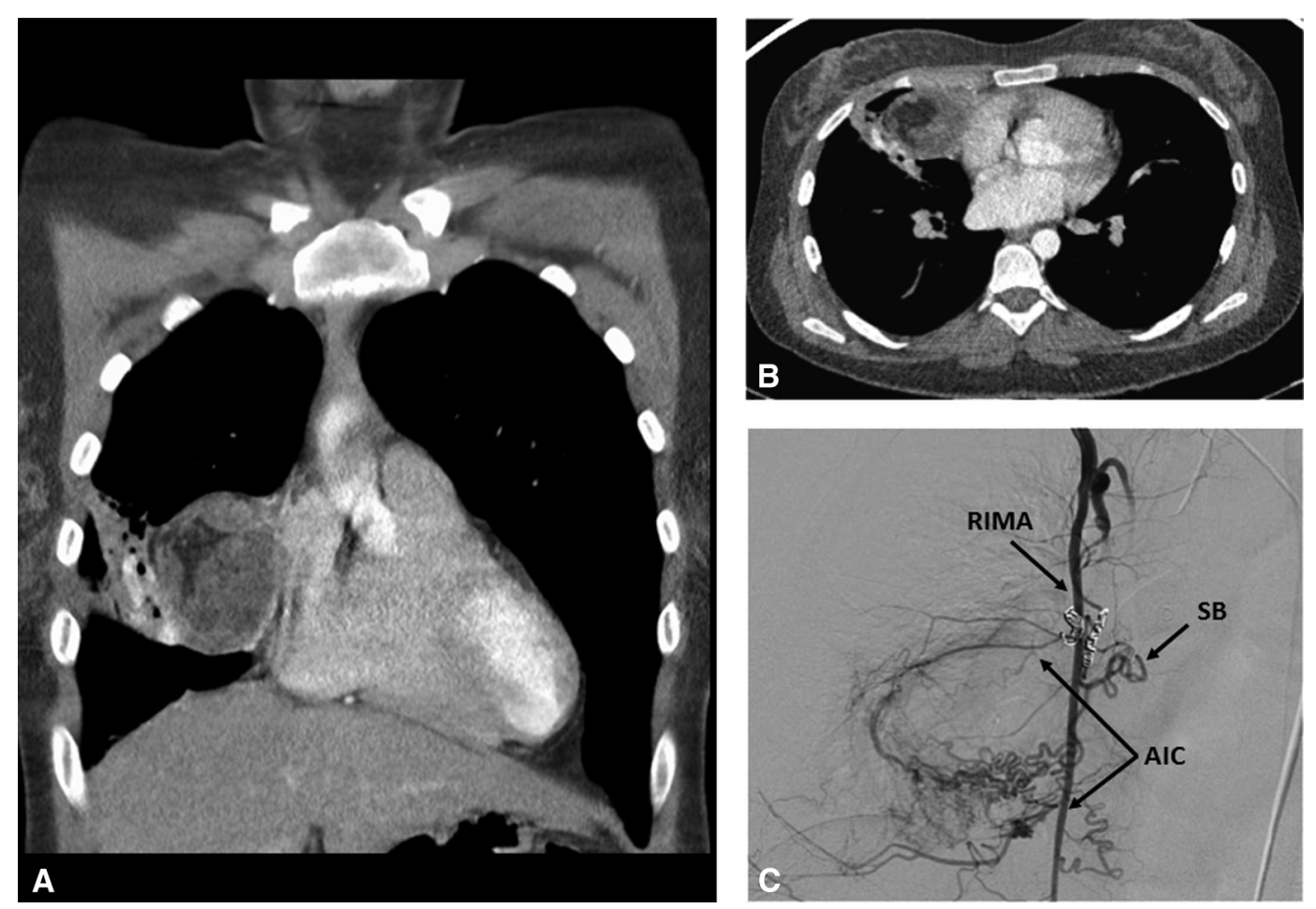

FIGURE 1. Coronal (A) and axial (B) computed tomography images of the right middle lobe lung mass. C, Angiography images demonstrating parasitized systemic arterial supply originating from the right internal thoracic artery, including anterior intercostal branches and sternal branches. RIMA, Right internal mammary artery; $S B$, sternal branch; $A I C$, anterior intercostal. 


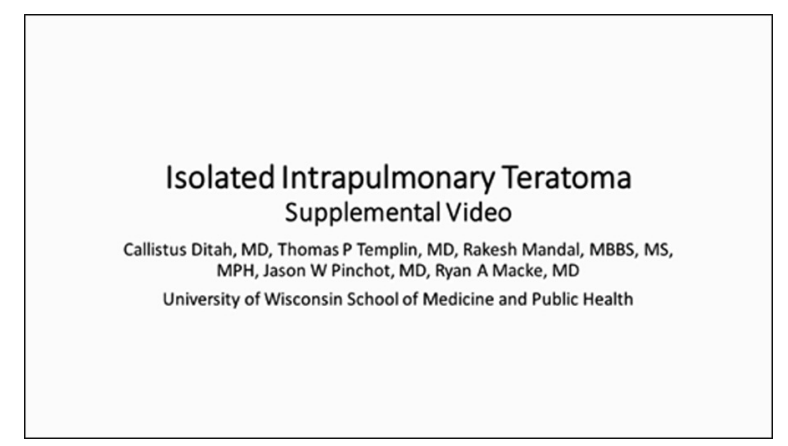

VIDEO 1. Associated video provides additional computed tomography, angiography, and pathology images, as well as additional discussion of specific aspects of the presented case. Video available at: http://www. jtcvsonline.org/article/S0022-5223(16)30876-5/addons.

associated large intrapulmonary mass, eventually discovered to be a mature teratoma after embolization and surgical resection.

\section{CASE SUMMARY}

A 19-year-old woman was referred with a 2-day history of moderate-volume hemoptysis with bright red blood. She also reported a 5-year history of a chronic, nonproductive cough and recurrent pneumonias during adolescence. She was a lifetime nonsmoker and denied any recent fevers, chills, night sweats, or unintentional weight loss. Chest computed tomography (CT) obtained on presentation revealed a large heterogeneous lung mass in the right middle lobe with extensive surrounding bronchiectasis and abnormally large systemic arteries supplying the mass (Figure 1 and Video 1).

Because of ongoing hemoptysis and unclear diagnosis, embolization of the systemic feeding arteries was performed, including the right internal thoracic, bronchial, and inferior phrenic branches (Figure 1 and Video 1). In total, 5 mediastinal arterial branches were embolized, decreasing inflow to the mass by approximately $90 \%$.

She then underwent an uncomplicated right middle lobectomy, the initial approach by video-assisted thoracic surgery, but eventually required conversion to thoracotomy because of hilar desmoplastic adhesions. Estimated blood loss was minimal. She tolerated the procedure well and was discharged home on postoperative day 4 after an unremarkable hospital course. Final pathology was consistent with a mature intrapulmonary teratoma containing dermal, respiratory, gastrointestinal, pancreatic, and thymic benign tissue elements (Figure 2 and Video 1). Subsequent $\mathrm{CT}$ of the abdomen and pelvis was obtained, effectively ruling out a primary gonadal germ cell tumor or other site of disease.
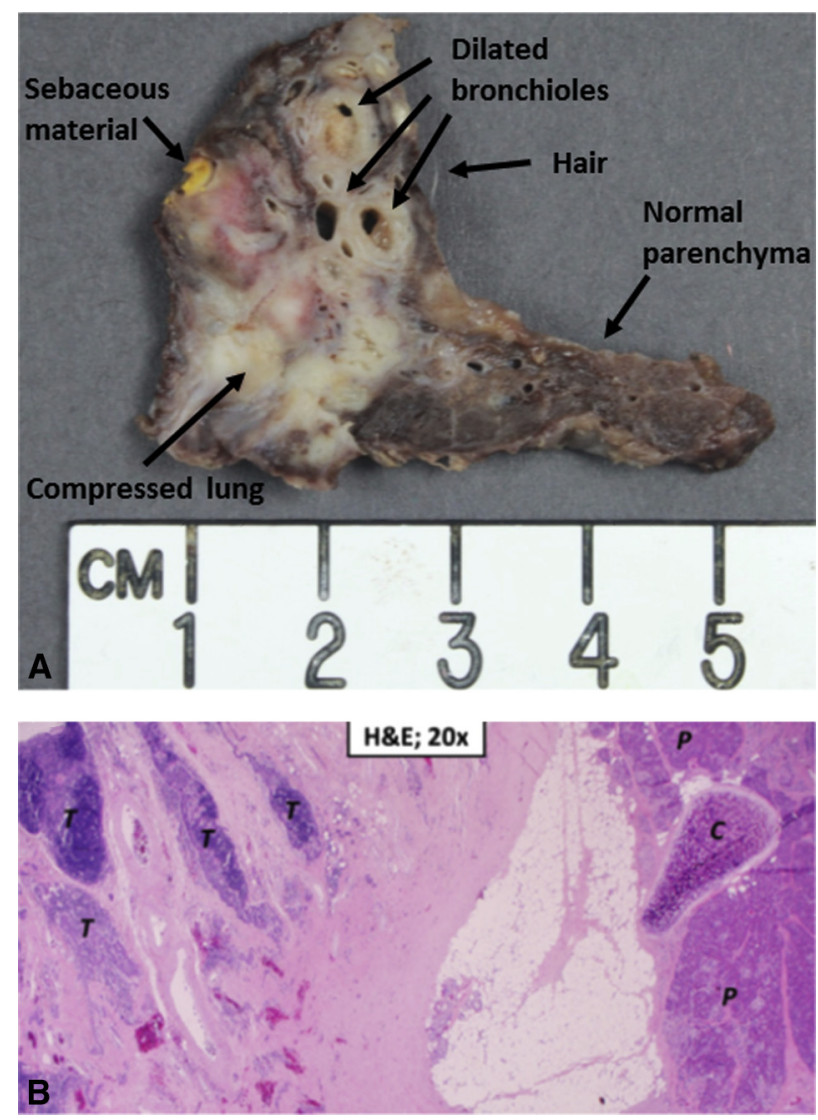

FIGURE 2. A, Gross image of a representative section of tumor with uninvolved lung tissue at the periphery and various tissue components. B, Mature teratoma revealing benign thymic tissue $(T)$ and mature components including cartilage $(C)$ and pancreatic tissue $(P)$ (hematoxylin-eosin $20 \times) . H \& E$, Hematoxylin-eosin.

\section{DISCUSSION}

Germ cell tumors account for approximately $10 \%$ to $15 \%$ of anterior mediastinal masses found in adults, with teratomas representing the most common subtype. ${ }^{1}$ Teratomas arise from pluripotent stem cells that undergo abnormal migration during embryonic development. In the case of mediastinal teratomas, these undifferentiated cells are thought to descend along with the primordial thymus arising from the third pharyngeal pouch/ventral foregut to rest in the mediastinum. ${ }^{1-3}$ These ectopic cells later differentiate into various cell types derived from any of the 3 embryonic germ layers, such as respiratory and intestinal epithelium (endoderm); muscle, bone, cartilage, and fat (mesoderm); and skin, sweat glands, hair, and teeth (ectoderm). Teratomas are defined by the presence of tissue from at least 2 germ layers. Further migration of these pluripotent cells along the forming lung bud, also 
derived from the ventral foregut, is thought to give rise to intrapulmonary teratomas with or without mediastinal extension. ${ }^{1-3}$

Approximately one third of intrapulmonary teratomas are symptomatic, with patients typically presenting in the third or fourth decade of life. ${ }^{1}$ Mass effect may result in atelectasis, bronchiectasis, pneumonia, or lung abscess with associated obstructive and infectious symptoms such as cough, fever, chest pain, and weight loss. ${ }^{1-3}$ Direct invasion or erosion caused by proteolytic or digestive enzymes produced by intestinal tumor components may lead to rupture into the bronchial airways with resulting hemoptysis and, in some cases, the more spectacular presentation of trichoptysis (expectoration of hair). ${ }^{1-4}$

Whereas the presentation of trichoptysis is considered by some to be pathognomonic of an intrapulmonary teratoma, diagnosis is otherwise rarely made before resection and histologic examination of the specimen. ${ }^{1,4}$ An anterior mass with heterogeneous attenuation seen on CT is strongly suggestive of a mediastinal teratoma. ${ }^{1}$ However, the differential diagnosis of an intrapulmonary mass with similar characteristics and symptoms may include infectious causes, such as a fungal mass, complex lung abscess, or hydatid cyst. ${ }^{1,2}$ A primary lung cancer or atypical malignancy also must be considered. In this particular case, the aberrant systemic vascular supply also raised the possibility of pulmonary sequestration. Systemic vascular supply of an intrapulmonary teratoma has been reported in one other similar case, which was also addressed with embolization. ${ }^{1}$

\section{CONCLUSIONS}

Approximately $80 \%$ of teratomas contain only mature tissue components and are considered benign. ${ }^{1}$ In the adult population, the presence of immature tissue components is associated with a poor prognosis. ${ }^{1,2}$ In rare cases, teratomas may undergo malignant transformation. ${ }^{1,2}$ Complete resection by anatomic or nonanatomic resection typically is necessary for diagnosis and is curative in cases of mature teratomas. Careful histologic analysis is required to determine whether the lesion contains immature components or foci of carcinoma. ${ }^{1}$ Chemotherapy may provide some benefit in cases of malignant transformation with distant metastasis. ${ }^{1}$ After pathologic confirmation of intrapulmonary teratomas, additional workup is needed to rule out a primary gonadal germ cell tumor with lung metastasis. $^{2}$

\section{References}

1. Macht M, Mitchell JD, Cool C, Lynch DA, Babu A, Schwarz MI. A 31-year old woman with hemoptysis and an intrathoracic mass. Chest. 2010;138: 213-9.

2. Dasbaksi K, Haldar S, Mukherkee K, Chakraborty U, Majumdar P, Mukherjee P. Intrapulmonary teratoma: report of a case and review of literature. Asian Cardiovasc Thorac Ann. 2016;24:574-7.

3. Eren MN, Balci AE, Eren S. Benign intrapulmonary teratoma: report of a case J Thorac Cardiovasc Surg. 2003;126:855-7.

4. Kang HS, Lee HY, Kang HH, Park CK, Lee SH, Moon HS. Intrapulmonary teratoma presenting with trichoptysis. J Thorac Oncol. 2013;8:126-7. 